\title{
Research on Cultural Industry Clusters Spatial Effects Hongjun $\mathrm{Niu}^{1, \text { a }}$ \\ ${ }^{1}$ Anyang Vocational and Technical College, Anyang, Henan, China, 455000 \\ ${ }^{\mathrm{a} e m a i l,}$
}

Keywords: Cultural Creative Industries, Clusters Development, Spatial Structure, Economic Effects

\begin{abstract}
From an economic point of view the area, regional economic space based on the similarity of economic relations based on geographical commonality and the composition, structure or economic resources, and cultural and creative industry cluster is the organizational form of such economic relations. Cultural and creative industry clusters, as a new industrial organization of space and optimal resource allocation model organizational model, with economies of scale, cost savings space effect, a chain reaction of innovation, regional brand, competing effect and complementary effect six areas economic effects of regional economic output and growth have significant economic importance.
\end{abstract}

\section{Introduction}

Regional economic activity space as reality carrier, with the increasing specialization of regional economic activity, market dependence and inter-regional space tightness will continue to increase, the spatial structure of the economy will increasingly become an important part of the regional economy. Cultural and creative industries in the community since the era of knowledge economy showing cluster development trend, the greater the degree of relevance of their regional space, regional economic space more significant effect. Explore the cultural and creative industries cluster spatial effects of economic globalization and regional integration in the context of great economic significance for regional economic output and growth.

\section{The “Economic Mosaic” Phenomenon in Cultural and Creative Industries}

In the context of economic globalization and regional integration, market competition has from the business development strategy to industrial cluster strategy evolution. Industrial Clusters through economies of scale, synergy show competitive advantage as a regional economy to participate in international competition in the market of the main force. Since the 1970s, with the rapid development of the northern Italian tradition of industrial clusters emerge in international competition and comparative advantage of industrial clusters phenomenon has aroused wide attention. 80 years later, the development of Silicon Valley, Hollywood and the rise of high-tech industrial park in the world is to make industrial clusters become a focal point of economic growth of universal law. Fortune world are in these regions block creation. California has Silicon Valley, its total economic output corresponding to the first 11 countries in the ranking of the total economy. Italian annual exports of $\$ 20$ billion are provided primarily by the 66 high-tech cluster areas. India, about 100 clusters have created $60 \%$ of the Indian IT industry exports. Shengzhou City of Zhejiang Province, focused on more than 1100 tie manufacturer, is one of the world's two largest industrial clusters tie, tie annual 350 million products in the world market share of $40 \%$ domestic market share reached 90 \%. 90 years later, in the international economy and culture more developed countries or regions, are widespread spatial agglomeration cultural and creative industries, the development of better cultural and creative industry clusters, mostly in big cities. At present, it has formed a six industrial clusters. First, Beijing and Tianjin cultural and creative industry clusters, Beijing as the country's cultural center has become the core of the cluster has been formed eight regional centers of cultural and creative industries theatrical performances, radio and television, antiques transactions. Second, the cultural and creative industry clusters in Yangtze River Delta, the rapid development of Shanghai as a leader, driven by Hangzhou, Suzhou Industrial Design, Nanjing, 
interior design, advertising planning exhibition planning and other industries. Shanghai has started more than a dozen creative industries concentrated area and the goal is to become "International Creative Industry Center." Third, the Pearl River Delta cultural and creative industry clusters, including Guangzhou, advertising, film and television, media, IT and other Creative Industries has become a national demonstration zone and the first in China, Shenzhen proposed to create "design" so that the "creative industries" Shenzhen has become the dominant industries, scale film and television animation industry has been highest in the country. Hong Kong also depends on the particular human environment and economic status of a "creative hub of Asia." Fourth, the central cultural and creative industry clusters represented by the television broadcasting industry and animation industry has formed a unique creative industry chain. Fifth, Sichuan and Shaanxi cultural and creative industries cluster. Chongqing, Chengdu, Xi'an cultural and creative industries mainly network animation and game industry, of which Chengdu digital entertainment as one of the three cities in the country, with the country's first network game animation industry base. Sixth Hai Dian cultural and creative industry clusters, the clusters in the film, clothing and other industries have more features, including Kunming, painting, music, sculpture and modeling industry activities in Sanya, have regional characteristics. The six cultural and creative industry clusters form a grid-like massive economic zones have played a very important role in regional economic growth. According to statistics, in 2006 Beijing cultural and creative industries to achieve income of 51.74 billion RMB, Shanghai cultural and creative industries to achieve income of 03.17 billion RMB, Guangdong Province, cultural and creative industries to achieve a 68.05 billion RMB, the tertiary industry accounted for 10.6\%, respectively, 13.2\% and 25\%. In 2008 China's cultural and creative industries bucked the trend, the growth rate of the three regions Beijing, Shanghai, Guangdong and other cultural and creative industries in more than 20\%, far exceeding the region's economic growth. Visible, the contribution of cultural and creative industries on regional economic development is also growing.

\section{The Spatial Structure Mode and Economic Characteristics of Cultural and Creative Industries}

From a regional point of view of economics, economic space based on the similarity of economic relations based on the composition and geographical commonality, resources, or economic structure. Cultural and creative industries cluster is exactly a reflection of economic relations in spatial structure. It is based on cultural differences in the distribution of natural resources, through the interaction of various economic factors associated with capital flows between regions, talent flow, technology flow, information flow, logistics and other inter-communicate through shared infrastructure, to achieve mutual benefit and win-win economic space mode, the internal mechanism is a form of economic organization of industry and spatial structure of its nature. According to the stage of development of different regions, the spatial structure of cultural and creative industries has three modes. First set nuclear spatial structure. This usually occurs in the early industrial development, creative class select the location where conditions are better as a creative workplace, full use of existing cultural resources and development conditions, and seize the opportunity to become a regional growth pole. Meanwhile, the investment rate of return is relatively high, while the periphery of capital, labor, technology and other elements of gathering appeal the polarization effects of regional factors of production. The famous Hollywood film base is typical of this organizational model. This occurred mainly in the middle of industrial development, the performance of growth pole must have more and more market demand and talented personnel, and thus in the growth around the pole, there are some points in economic activity relative concentration, growth pole between these points and have complementary factors of production, thus becoming the regional development by relying on an axis. This is mainly in the late industrial development, the performance with the further development of point-axis system, the axis in the contact points between the different levels has been strengthened between the point and the point will form a cross of transportation, communications and power supply network. Such as the layout of the printing industry in Zhejiang Province in the development process, with emphasis on build Hangzhou, 
Ningbo, the printing characteristics of the four blocks as the core industries, promote development of related industries trade publishing industry, paper industry, focusing on industrial blocks between linkages to form a strong radiation publishing industry network.

Compared with the traditional industries, cultural and creative industry clusters have the following economic characteristics: first, a common cultural background and institutional environment that is rooted in nature and irreplaceable social capital. Leading corporate culture based on the cluster resource, knowledge original core of the knowledge-intensive enterprises. Second, the homogeneity and relevance of cultural and creative enterprises within the cluster in the same, similar and complementary cultural and economic activities between enterprises closely linked and interdependent, sharing of resources and the combined effect of the spillover effect is easily formed. Cultural and creative industries network in the main economic activities and a variety of organizations to achieve flexible specialization of production and business activities through specialization and economic cooperation, in order to obtain the maximum external economy. Although the cultural and creative enterprises can define specific industry areas, but because of cultural and creative industries cover a wide range, it contains related businesses, general and Standard Industrial Classification system inconsistencies. Its geographic scope and the existing administrative boundaries is difficult to have accurate boundary. It is because of the cultural and creative industry agglomeration has a traditional industrial cluster different special economic characteristics and industrial advantages, which makes possible the rapid rise of cultural and creative industries, regional economic development and become a pillar industry in the region to improve the core competitiveness It plays an important role.

\section{The Analysis of the Spatial Effects of Cultural and Creative Industry Cluster}

Cultural and creative industry clusters, as a new industrial organization of space and optimal resource allocation model organizational model in regional economic activity showed a strong spatial effect on output. To sum up, mainly in the following six areas:

The Scale Economies Effects. Focus on cultural and creative industries in space, you can bring economies of scale. When the relevant companies produce cluster, make specialization in a unique way to promote the development of upstream and downstream enterprises in depth, to promote expansion of the value chain related links, consequent financial, accounting, insurance, management, consulting and infrastructure other aspects of the demand for services. Thus creating a huge opportunity to attract more enterprises to enter the transversely extending its scale will be expanded, so that businesses in the region to achieve the optimal level of agglomeration economies of scale and enhance their competitive advantage.

Cost Saving Effects. Because of the proximity between the cluster within the cultural and creative enterprises geographical frequent exchanges and cooperation relations more stable, easier to build mutual trust and interdependent relations of cooperation, negotiation help to reduce costs and improve the efficiency of execution of the contract, thus greatly reducing the chance of behavior in; and because of the spatial distance is shortened to reduce transportation costs and the cost of information exchange between enterprises, enterprises can save time and resources, thus greatly reduce product costs and improve competitive advantage. On the other hand, the cluster has a lot of market information and creative human resources, enterprise in a short time, at a lower cost of supply and demand information search necessary to find suitable human resources, search costs for this enterprise paid and transaction costs are greatly reduced; in addition to the deeper level of specialization, companies focus on certain aspects of the production of products, can lower management costs.

Innovative Knock-On Effect. Cultural and creative industries are the knowledge and technology-intensive industries, high technology achievements conversion efficiency, faster product updates, with strong conductivity and spillovers. When cultural and creative industries appear innovative or upgrade production techniques, technology and product features of the region, it tends to have first attracted other industries closely related to innovation. And this innovation directly related upstream and downstream industries will further spread to form a continuous innovation 
effect. Language cluster of companies in the long-term focus on the details of the value chain process is easier in the form of differentiated innovative activities, development of new products and new technology. Coupled with similar enterprises Agglomeration generated strong competitive pressures, forcing companies will continue to expand innovation, and constantly improve the technological level and management level. Within the cluster, enterprises adjacent to each other, in close cooperation, a business innovation can easily spill over to other enterprises and peer companies produce good demonstration and incentives to promote the transfer and diffusion of technology.

Regional Brand. Cultural and creative industries rely on community rich cultural resources and a strong driving force for innovation to create a regional brand value, to obtain the integration of economic and community credibility in the region. Some of the world famous creative industry gathering area has such a brand, such as Hollywood movies, opera in London, Paris, fashion, Beijing antiques, all with this reputation effect. This effect covers the regional characteristics and cultural history, is a cluster of many brand of refined and concentrated more than a single corporate brand image, more inclusive, iconic and stability. At the same time, enterprises within the cluster shared regional brand, has a more powerful competitive advantage.

Competing Effects. Enterprise cluster node only chain of cultural and creative industries value chain, they focus on the advantages of geographical space that will be in all aspects of cultural and creative industries value chain organically linked, thereby enabling the value chain downstream developers, supply forming a cooperative, competitive, and overall learning between suppliers, manufacturers and vendors. In certain regions of space, brought together a number of cultural and creative enterprises will inevitably lead to fierce competition in the market. But this business will have an incentive to compete. On the one hand the existence of a large number of competitors, forcing enterprises to continuous technological innovation, improves product and service. On the other hand, the presence of competitors on the market to expand capacity, increase in the needs of industry and improve industry awareness so has a positive significance. Thus, the competition is not only to enhance the competitiveness of industry cluster, and make the competition between enterprises to expand at a higher level. Competitive outcome is often a "win-win" or "win-win." The presence of competition and cooperation mechanism to enable enterprises to the industrial area than those scattered in various parts of the business, more competitive, more into the forefront of the industry in this area.

Complementary Effect. Division of labor relations in the cultural and creative industries closely spaced spatial structure, so that between enterprises, enterprises and universities (or research institutions) between more closely, to maximize the sharing of resources, complementary advantages. Since the industrial linkage cultural and creative industries and digital, network, telecommunications, manufacturing, marketing and other relatively large, some mutual penetration, especially for the growing dependence of digital technology, coupled with customer and consumer demand is diffusion type and diversified, so they are bound to use more, such as broadband networks, databases, information resources, digital processing and production of land, water, electricity, communications and other public infrastructure and public services, but also industrial policy, taxation policy, employment policy, public management systems support. This gathering through space to share the benefits of public services, investment and services helps to get government and other public bodies, namely "centralized economy" and thus overcome the single enterprise in the use of resources are not economic phenomenon, made good synergies.

\section{Acknowledgements}

Fund Project: 2015 Henan Science and Technology Agency Soft Science Project (152400410338)

\section{References}

[1] Li Jinxia. Anhui Science and Technology, Vol. 2 (2007) No 19, p.144-145

[2] IUD. Chinese Government Information Network, www.ccgov.org.cn 
[3] Chinese Financial Network, www.china.fi-nace.net

[4] Sun Jie. Productivity Research, Vol. 1 (2009) No 27, p.57-60

[5] Zhu Xuguang. Economic Forum, Vol. 2 (2009) No 27, p.21-23 